\title{
Author's Reply to Carracedo-Martínez E Comment on: "Prescribing of Rosiglitazone and Pioglitazone Following Safety Signals: Analysis of Trends in Dispensing Patterns in The Netherlands from 1998 to 2008"
}

\author{
Bruno H. C. Stricker
}

Published online: 24 September 2014

(C) Springer International Publishing Switzerland 2014

I would like to thank Dr Carracedo-Martínez for his interest in our work, and for his valuable comments [1]. Obviously, health insurance companies do not invent such measures out of the blue but on the basis of warnings from regulatory authorities such as the European Medicines Agency. 'Dear Healthcare Professional Communications' (DHPCs) on this issue had already been sent before July 2007, and the decline in prescribing already occurred before that month [2]. It is likely that several local and regional guidelines also changed and further contributed to the decline. Such consequences from DHPCs are helpful to endorse safer prescribing. In this case, health insurers reemphasized that thiazolidines should be prescribed to noninsulin-dependent diabetics with a contra-indication for metformin and sulfonylureas, or in those on double or triple therapy with metformin, a thiazolidine, and a sulfonylurea. From an epidemiological viewpoint, such measures are considered as intermediates rather than as direct causal factors for prescription decline.

Funding and conflict of interest No sources of funding were used to assist in the preparation of this reply. Bruno Stricker has no conflicts of interest that are directly relevant to the content of this study.

\section{References}

1. Carracedo-Martínez E. Comment on: "prescribing of rosiglitazone and pioglitazone following safety signals analysis of trends in dispensing patterns in The Netherlands from 1998 to 2008”. Drug Saf. 2014. doi:10.1007/s40264-014-0227-y.

2. Ruiter R, Visser LE, van Herk-Sukel MP, Geelhoed-Duijvestijn PH, de Bie S, Straus SM, Mol PG, Romio SA, Herings RM, Stricker BH. Prescribing of rosiglitazone and pioglitazone following safety signals: analysis of trends in dispensing patterns in The Netherlands from 1998 to 2008. Drug Saf. 2012;35:471-80.
B. H. C. Stricker ( $\square)$

Department of Epidemiology, Erasmus Medical Center, P. O. Box 2040, 3000 CA Rotterdam, The Netherlands

e-mail: b.stricker@erasmusmc.nl 